\title{
The Adaptive Metabolism of D-Galactose in Aspergillus nidulans
}

\author{
By C. F. ROBERTS \\ Microbiology Unit, Department of Biochemistry, University of Oxford
}

(Received 19 September 1962)

SUMMARY

Methods are described for the growth of Aspergillus nidulans in submerged culture. In experiments with intact organisms D-galactose was oxidized by an inducible enzyme system; D-fucose was a poor inducer of this system. Mutants isolated by their failure to grow on galactose as sole carbon source were defective in the oxidation of galactose.

\section{INTRODUCTION}

Powerful techniques for genetic analysis have been developed for the mould Aspergillus nidulans (Pontecorvo et al. 1953; Pontecorvo \& Käfer, 1958) but relatively little work has been done on the biochemistry of the organism (Hockenhull, 1950; Singh \& Walker, 1956) and few attempts made to combine genetical and biochemical investigations (Shepherd, 1956). Following the elucidation of the Leloir pathway of galactose metabolism (reviewed by Kalckar, 1958) genetically determined lesions in the enzymes concerned were described in man (Kalckar, 1959), in Saccharomyces cerevisiae (Robichon-Szulmajster, 1958) and in certain enterobacteria (Kalckar, Kurahashi \& Jordan, 1959; Fukasawa \& Nikaido, 1961; Soffer, 1961). Regulation of the formation of the enzyme system has also been studied in some bacteria (Yarmolinsky, Jordan \& Weismeyer, 1961 ; Buttin, 1961; Fukasawa, Jokura \& Kurahashi, 1962). Mutants of $A$. nidulans which fail to grow on galactose have been isolated and analysed genetically (Roberts, 1963); the present paper describes investigations with intact organisms of the metabolism of galactose by the wild type organism and by the galactose mutants.

\section{METHODS}

Organisms. Aspergillus nidulans strain bi1;w3 (a biotin-requiring auxotroph with white conidia) was obtained from the Department of Genetics, Glasgow University (Pontecorvo et al. 1953). It has the wild type property of utilizing D-galactose as sole carbon source for growth and was the strain from which a number of mutants which did not grow on galactose were isolated following ultraviolet irradiation (Roberts, 1959, 1963). Cultures were maintained on slopes of malt extract agar.

Media. Malt extract agar: Malt extract, $20 \mathrm{~g}$; ; peptone $1 \mathrm{~g}$.; glucose $20 \mathrm{~g}$.; British Drug Houses agar, 25 g. were dissolved in tap water (1 1.) and autoclaved at $120^{\circ}$ for $15 \mathrm{~min}$; the medium was then at $\mathrm{pH} 6 \cdot 5-7 \cdot 0$.

The basal medium (BM) used was the standard minimal medium for Aspergillus nidulans (Pontecorvo et al. 1953) but prepared without a carbon source. A trace 
salts solution was used in the present experiments, it contained $(\mathrm{mg} . / 100 \mathrm{ml}$.): $\mathrm{FeSO}_{4} \cdot 7 \mathrm{H}_{2} \mathrm{O}, 100 ; \mathrm{ZnSO}_{4} \cdot 7 \mathrm{H}_{2} \mathrm{O}, 880 ; \mathrm{CuSO}_{4} .5 \mathrm{H}_{2} \mathrm{O}, 40 ; \mathrm{MnSO}_{4} \cdot 4 \mathrm{H}_{2} \mathrm{O}, 15 ;$ $\mathrm{Na}_{2} \mathrm{~B}_{4} \mathrm{O}_{7} .10 \mathrm{H}_{2} \mathrm{O}, 10 ;\left(\mathrm{NH}_{4}\right)_{6} \mathrm{Mo}_{7} \mathrm{O}_{24} \cdot 4 \mathrm{H}_{2} \mathrm{O}, 5$. One litre of basal medium contained $\mathrm{NaNO}_{3}, 6.0 \mathrm{~g}$.; $\mathrm{KCl}, 0.52 \mathrm{~g}$; $\mathrm{KH}_{2} \mathrm{PO}_{4}, 1.52 \mathrm{~g}$; $1.0 \mathrm{ml}$. trace salts solution. This medium was adjusted to $\mathrm{pH} 6.5$ before autoclaving $\left(120^{\circ}, 15 \mathrm{~min}\right.$.) and $\mathrm{MgSO}_{4}$ (to $0.52 \mathrm{~g} . / 1$.) added as a sterile solution when the medium had cooled, to avoid precipitation of magnesium phosphate. Biotin was supplied in excess at $0.5 \mathrm{mg} . / 1$. Carbohydrates were sterilized separately by autoclaving at $115^{\circ}$ for $15 \mathrm{~min}$. and added at a final concentration of $10 \mathrm{~g}$./l.; conidia of $A$. nidulans are water repellent and the wetting agent Tween 80 was added to all liquid media $\left(1 / 10^{4}\right)$ to bring conidia into suspension.

Preparation of inocula. A suspension of conidia was plated on malt extract agar to yield 25-100 colonies/plate and the plates incubated at $37^{\circ}$ for 6 days by which time heavy sporulation had occurred. The conidia were harvested by drawing a sterile wire across the plate, collected in a screw cap bottle containing $0.85 \% \mathrm{NaCl}$ solution + Tween 80 and shaken on a Microid shaker for 20 min. to break up spore clumps.

Culture vessels. Modified 11 . and 2 l. conical flasks were used. Each flask had four internal baffles consisting of vertical invaginations of the wall of the vessel $1 \mathrm{~cm}$. deep and $3 \mathrm{~cm}$. high which just touched the surface of the medium when the flask was at rest. A water-repellent silicone film (Hopkins \& Williams silicone fluid M.S. 1107) was applied to the internal surface of the flasks. The baffles dispersed the mycelial pellets and aided aeration, while the silicone film prevented accumulation of pellets above the wash line of the medium.

Culture conditions. Flasks containing one-fifth their volume of medium were inoculated with suspensions of conidia to a final concentration of about $3 \times 10^{6}$ conidia/ml. medium. They were incubated at $30^{\circ}$ with vigorous swirling (200 rotations/min.) on a gyrorotary shaker (New Brunswick Instrument Co.). These conditions of culture yielded dense suspensions of small pellets of mycelium about $0.05 \mathrm{~mm}$. in diameter which were formed by aggregation of germinating conidia. The suspensions can be handled quantitatively by pipetting, but variations observed in measuring rates of gas exchange (Table 1) might have been due to differences in the size and texture of the pellets.

Preparation of suspensions of organisms. Mycelial pellets were harvested on a sintered glass filter (No. 2 grade), resuspended in three changes of deionized water, washed twice with distilled water and finally suspended in 0.04 M-potassium phosphate buffer (pH 6.5). Dry weights were determined after washing samples on the filter and drying overnight at $105^{\circ}$ in aluminium foil cups. The suspensions used contained 1.0-2.5 mg. dry weight organisms $/ \mathrm{ml}$.

Estimations. Manometric assays of $\mathrm{O}_{2}$ uptake or $\mathrm{CO}_{2}$ production were done by conventional methods (Umbreit, Burris \& Stauffer, 1949). The manometer flasks contained $2.0 \mathrm{ml}$. suspension (equiv. 2.0-5.0 mg. dry weight organism) in the main compartment, $0.5 \mathrm{ml}$. $0.01 \mathrm{~m}$ substrate solution (or $0.5 \mathrm{ml}$. water for controls) in the side arms, and $0.2 \mathrm{ml}$. of $20 \% \mathrm{KOH}$ in the centre well (when $\mathrm{O}_{2}$ uptake was measured). The temperature was $30^{\circ}$. There was a linear relationship between the rate of oxygen uptake and dry weight of organisms up to at least $7.5 \mathrm{mg}$. dry weight organism/flask. 
The disappearance of sugar from the medium was followed under conditions simulating as far as possible those in the manometer flasks. An open $100 \mathrm{ml}$. conical flask containing $20 \mathrm{ml}$. of organism suspension and $5.0 \mathrm{ml}$. of $0.01 \mathrm{~m}$ substrate was shaken in the manometer bath and samples taken periodically. Organisms were removed by filtration and the amount of reducing sugar in the filtrate estimated by the arsenomolybdate method (Nelson, 1944).

Chemicals. D-Galactose was obtained from T. Kerfoot and Co., (Vale of Bardsley, Lancs.). Glucose contamination of the galactose was estimated by the glucose oxidase method (Huggett \& Nixon, 1957) and did not exceed $2 \%$ in any sample. D-Fucose was obtained from L. Light and Co. (Colnbrook, Bucks., England).

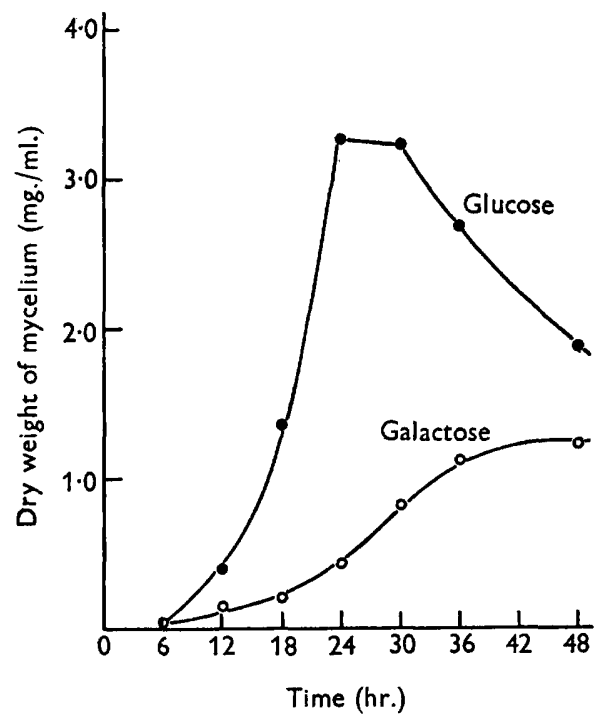

Fig 1

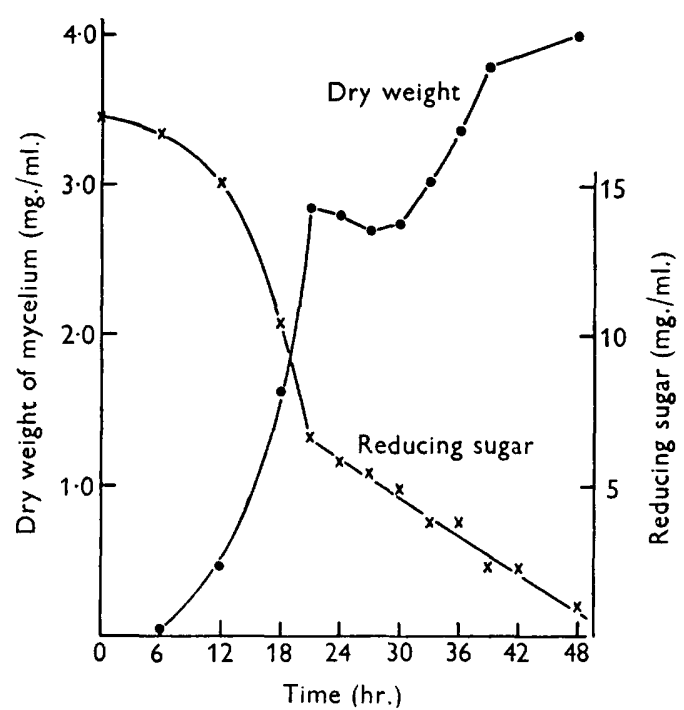

Fig. 2

Fig. 1. Growth of Aspergillus nidulans strain bi1;w3 in submerged culture grown in basal medium $(\mathrm{BM})+$ biotin with $1 \%$ glucose $(0-0)$ or $1 \%$ galactose $(0-0)$ as carbon source. Samples were taken for dry weight determinations at the times shown.

Fig. 2. Diauxie of Aspergillus nidulans strain bi1 ;w3 grown in submerged culture with a mixture of $0.75 \%$ glucose and $0.75 \%$ galactose. Dry weights (0-0) and total reducing sugar $(x-x)$ in the medium (calculated as galactose) were determined at the times shown.

\section{RESULTS}

Growth of Aspergillus nidulans strain bi1;w3 with glucose or galactose as carbon source

Galactose is a comparatively poor carbon source for Aspergillus nidulans, the rate of growth and the yield of organism being substantially less than with glucose (Fig. 1). The long lag period in growth on galactose and the typical diauxie (Monod, 1942) observed when a culture was supplied with a mixture of glucose and galactose suggested that galactose is utilized adaptively (Fig. 2). 
Uptake and oxidation of glucose and galactose by Aspergillus nidulans strain bil;w3

Organisms were grown with glucose or galactose as carbon source and then tested for ability to take up and to oxidize these sugars. Glucose is metabolized by a constitutive enzyme system and galactose by an inducible system, for organisms grown on galactose immediately take up and oxidize both sugars, whereas organisms grown on glucose metabolize glucose but cannot oxidize galactose and only remove it from the medium at a low rate (Table 1). Differences in specific rates of oxidation and sugar uptake are probably due to variation in the size and texture of the mycelial pellets. The rate of oxidation of galactose by galactose-grown organisms was about $40 \%$ that for glucose oxidation; the rate of galactose uptake was $60 \%$ that of glucose uptake.

Table 1. Adaptive uptake and oxidation of $\mathrm{D}$-galactose by

Aspergillus nidulans, strain bi1;w3

\begin{abstract}
Organisms were grown in basal medium (BM) + biotin with $1 \%$ glucose or $1 \%$ galactose as carbon source. Washed organisms were suspended in $0.04 \mathrm{M}$-phosphate buffer (pH 6.5) and the rates of oxygen consumption and sugar uptake determined as described in Methods.
\end{abstract}

\begin{tabular}{|c|c|c|c|c|c|c|}
\hline \multirow[b]{3}{*}{$\begin{array}{l}\text { Carbon source } \\
\text { for growth }\end{array}$} & \multirow{3}{*}{$\begin{array}{l}\text { Growth } \\
\text { period } \\
\text { (hr.) }\end{array}$} & \multicolumn{3}{|c|}{$\begin{array}{c}\text { Rate of oxygen uptake } \\
(\mu \mathrm{l} / \mathrm{hr} \cdot / \mathrm{mg} \text {. dry weight organism) }\end{array}$} & \multirow{2}{*}{\multicolumn{2}{|c|}{$\begin{array}{l}\text { Rate of sugar uptake } \\
\text { ( } \mu \text { moles/hr./mg. } \\
\text { dry weight organism) }\end{array}$}} \\
\hline & & \multirow[b]{2}{*}{$\begin{array}{l}\text { Endo- } \\
\text { genous }\end{array}$} & \multicolumn{2}{|c|}{$\begin{array}{l}\text { Increase over } \\
\text { endogenous }\end{array}$} & & \\
\hline & & & $\begin{array}{l}\text { Glucose } \\
\text { added }\end{array}$ & $\begin{array}{l}\text { Galactose } \\
\text { added }\end{array}$ & Glucose & Galactose \\
\hline \multirow[t]{8}{*}{ Glucose } & 16 & 16 & 45 & $\mathbf{1}$ & - & - \\
\hline & 15 & 14 & 69 & $\mathbf{3}$ & - & - \\
\hline & 15 & 11 & 48 & 5 & - & - \\
\hline & 15 & 16 & 61 & 2 & $1 \cdot 82$ & 0.04 \\
\hline & 15 & 14 & 47 & $\mathbf{0}$ & 1.78 & $0 \cdot 11$ \\
\hline & 15 & 19 & 64 & 4 & 1.96 & $0 \cdot 15$ \\
\hline & 15 & 20 & 37 & 0 & $1 \cdot 54$ & 0.07 \\
\hline & Mean & 16 & 53 & 2 & $1 \cdot 78$ & 0.08 \\
\hline \multirow[t]{4}{*}{ Galactose } & 16 & 11 & 44 & 20 & - & - \\
\hline & 18 & 15 & 67 & 18 & $2 \cdot 20$ & $1 \cdot 10$ \\
\hline & 21 & 17 & 55 & 25 & 1.50 & 1.00 \\
\hline & Mean & 14 & 55 & 21 & 1.85 & 1.05 \\
\hline
\end{tabular}

Endogenous rates of oxygen uptake were high and the respiratory quotient ( 0.7 for glucose-grown organisms, 0.8 for galactose-grown organisms) are consistent with a fat being the substrate (cf. Singh \& Walker, 1956). Starvation of organisms by incubation in buffer or in a medium without a carbon source resulted in parallel decrease of endogenous and exogenous rates. During the oxidation of glucose and of galactose the R.Q. was $\mathbf{1} \cdot 0$.

A substantial proportion of the substrate was assimilated. This was studied by two methods, both based upon the assumption that complete oxidation of the substrate requires 6 equivalents of oxygen. In the first method the oxygen consumed in the oxidation of a known quantity of substrate was measured, corrected for endogenous respiration, and the proportion of substrate assimilated estimated from the difference between observed and expected quantities of oxygen consumed 


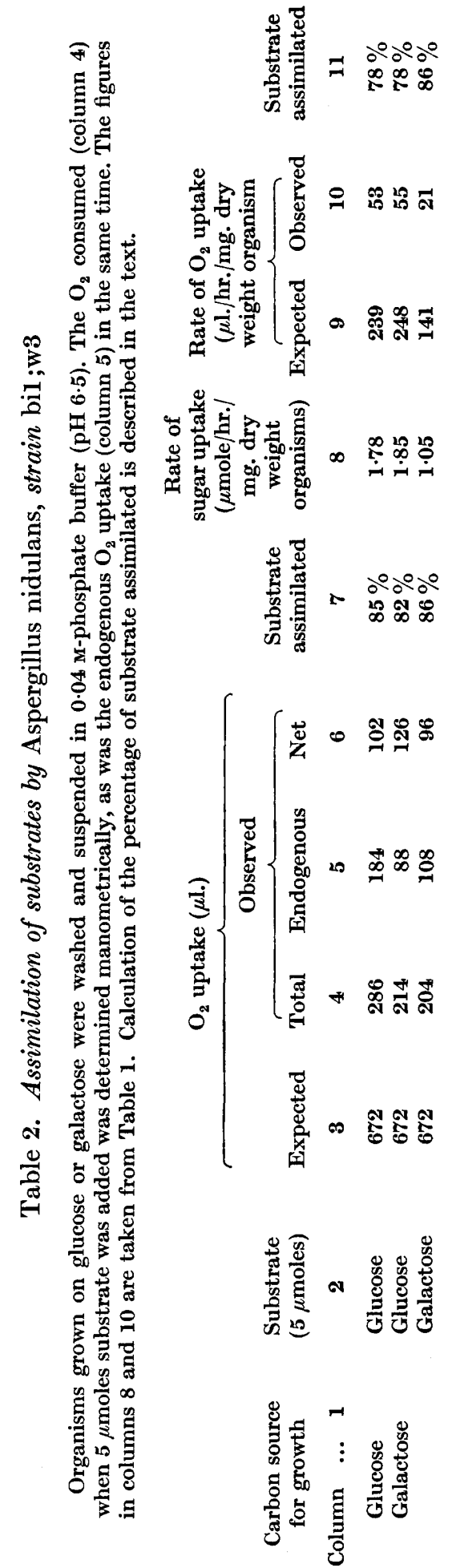


(Table 2, columns 3-7). In the second method the rate of oxygen uptake expected from the rate of sugar uptake was calculated and the proportion of substrate assimilated estimated from the difference between the expected and observed rates of oxygen uptake (Table 2, columns 8-11). The two methods yielded results in close agreement; about $80 \%$ of added glucose was assimilated and about $85 \%$ of the galactose.

Induction of the galactose oxidation system in Aspergillus nidulans strain bil ;w3

The galactose-oxidizing system was induced by incubation of organisms in a growth medium in the presence of galactose. Organisms were grown in basal medium $(\mathbf{B M})+$ glucose for $\mathbf{1 5} \mathrm{hr}$., washed aseptically and resuspended in fresh

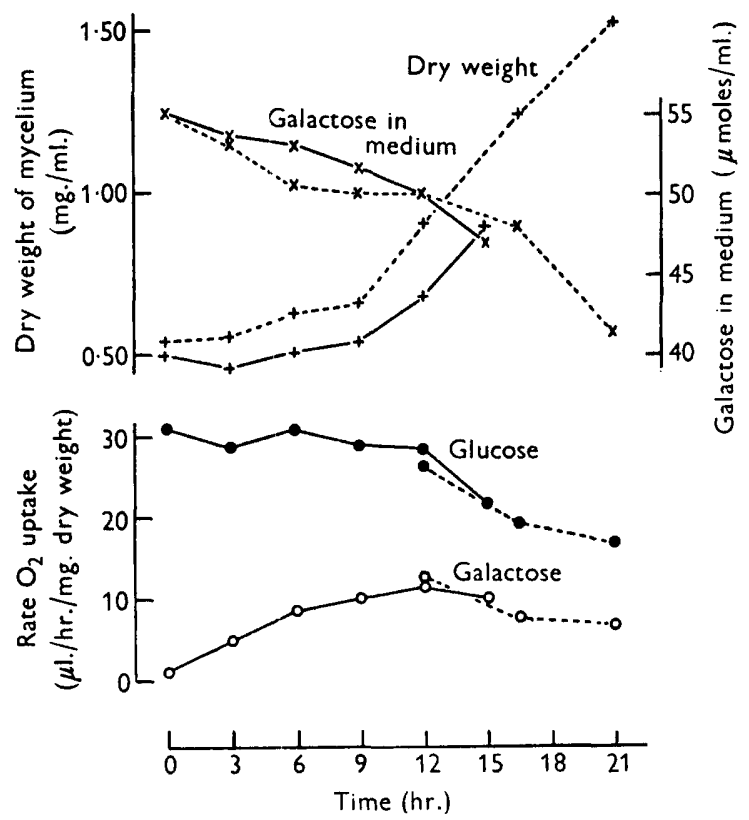

Fig. 3. Induction of the galactose oxidation system in Aspergillus nidulans strain bi1 ;w3. Organisms were grown for $15 \mathrm{hr}$. in basal medium (BM) + biotin with $1 \%$ glucose as carbon source, harvested, washed aseptically by centrifugation and resuspended in fresh basal medium $(\mathrm{BM})+$ biotin, with $1 \%$ galactose and incubated at $30^{\circ}$ on the shaker. Samples were taken periodically and the dry weight yields of organisms and the galactose remaining in the medium determined. Rates of oxidation of glucose $(-)$ and galactose $(\mathrm{O}-\mathrm{O})$ were determined manometrically and are shown after subtraction of the endogenous values. The curves were derived from two separate experiments, one for the induction period 0-15 hr. (solid lines) and one for the period 12-21 hr. (broken lines).

BM + galactose. The results of two such induction experiments are shown in Fig. 3. There was a lag in growth for about $9 \mathrm{hr}$. which corresponds to the lag previously observed in the growth of conidia on galactose (Fig. 1) and in diauxie on a mixture of glucose and galactose (Fig. 2). During this lag period there was a slow uptake of galactose and a steady increase in the specific rate of galactose oxidation to a maximum at about $12 \mathrm{hr}$., when it was $40 \%$ of that of glucose oxidation. The de- 
crease in rates of oxidation after incubation for $15 \mathrm{hr}$. (30 hr. total incubation) probably resulted from limitation of $\mathrm{O}_{2}$ uptake by the size of the pellets and the accumulation of inert material such as walls of empty mycelium.

D-Fucose (6-deoxy-galactose) is an inducer of the enzymes for galactose utilization in Escherichia coli (Buttin, 1961). Aspergillus nidulans does not utilize D-fucose for growth and organisms grown in the presence of fucose (with glycerol as carbon source) do not oxidize the sugar. When $A$. nidulans strain bil; w3 was grown with glycerol +fucose or galactose there was significant induction of the galactose oxidation system in both cases; but fucose was only one-third as effective as galactose as an inducer (Table 3). This was also the case when the organism was grown on glucose and then incubated in a fresh growth medium with glycerol + fucose or galactose.

\section{Table 3. Induction of the galactose oxidation system in} Aspergillus nidulans strain bi1; w3 by $\mathrm{D}$-fucose

In Experiments 1 and 2 organisms were grown for $18 \mathrm{hr}$. in basal medium (BM) + biotin with $1 \%$ glycerol and inducer as shown. In Experiment 3 organisms were grown for $15 \mathrm{hr}$. in basal medium $(\mathrm{BM})+$ biotin with $1 \%$ glucose; they were then harvested, washed aseptically by centrifugation and resuspended in basal medium (BM) + biotin + the carbohydrates shown, and incubated for $15 \mathrm{hr}$. Rates of galactose oxidation were determined manometrically.

\begin{tabular}{|c|c|c|}
\hline & $\begin{array}{r}\text { Rates o } \\
(\mu \mathrm{l} . / \mathrm{hr} . / \mathrm{mg} . \mathrm{drJ}\end{array}$ & $\begin{array}{l}\text { lptake } \\
\text { ght organism) }\end{array}$ \\
\hline Organisms grown on & Endogenous & $\begin{array}{c}\text { Increase } \\
\text { when } \\
\text { galactose } \\
\text { added }\end{array}$ \\
\hline Experiment 1 & & \\
\hline Glycerol & $13 \cdot 8$ & $1 \cdot 8$ \\
\hline Glycerol + 0.01 M-fucose & $14 \cdot 1$ & $3 \cdot 1$ \\
\hline Glycerol + 0.01 M-galactose & $13 \cdot 9$ & $7 \cdot 6$ \\
\hline Experiment 2 & & \\
\hline Glycerol & $17 \cdot 2$ & $1 \cdot 4$ \\
\hline Glycerol +0.05 x-fucose & $17 \cdot 1$ & $3 \cdot 9$ \\
\hline Glycerol + 0.05 M-galactose & $16 \cdot 6$ & $12 \cdot 4$ \\
\hline $\begin{array}{l}\text { Experiment } 3 \\
\text { Glucose } 15 \mathrm{hr} \text {. then: }\end{array}$ & & \\
\hline Glycerol & $22 \cdot 7$ & $\mathbf{1} \cdot \mathbf{2}$ \\
\hline Glycerol + 0.05 $\mathrm{m}$-fucose & $22 \cdot 8$ & $2 \cdot 6$ \\
\hline Glycerol + 0.05 M-galactose & $19 \cdot 7$ & $6 \cdot 9$ \\
\hline 0.05 M-galactose & $21 \cdot 5$ & $9 \cdot 8$ \\
\hline
\end{tabular}

Metabolism of galactose by galactose mutants of Aspergillus nidulans strain bi1;w3

The genetic analysis of a number of ultraviolet-induced galactose mutants of Aspergillus nidulans has resulted in recognition of five loci which control the metabolism of galactose in this organism (Roberts, 1963). These galactose mutants all grow normally with glucose as carbon source and are of two distinct phenotypes when tested for growth on galactose: one does not grow at all, while the other grows slowly, yielding non-sporing colonies which are morphologically abnormal. These slow-growing mutants are different from partial ('leaky') mutants which have been isolated by their poor growth on other sugars (e.g. maltose, lactose) in 


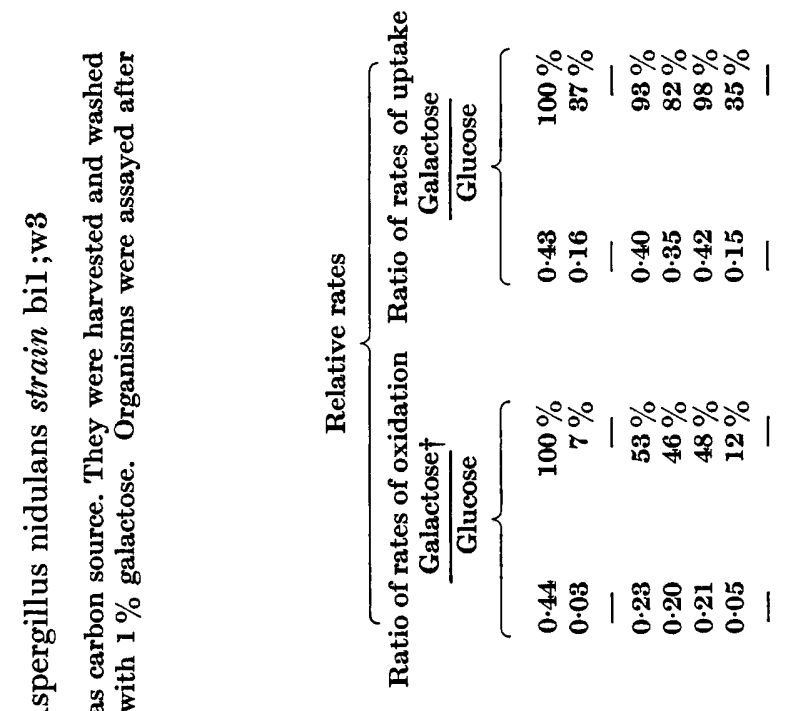

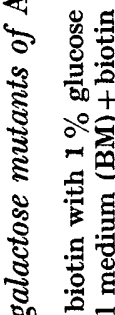

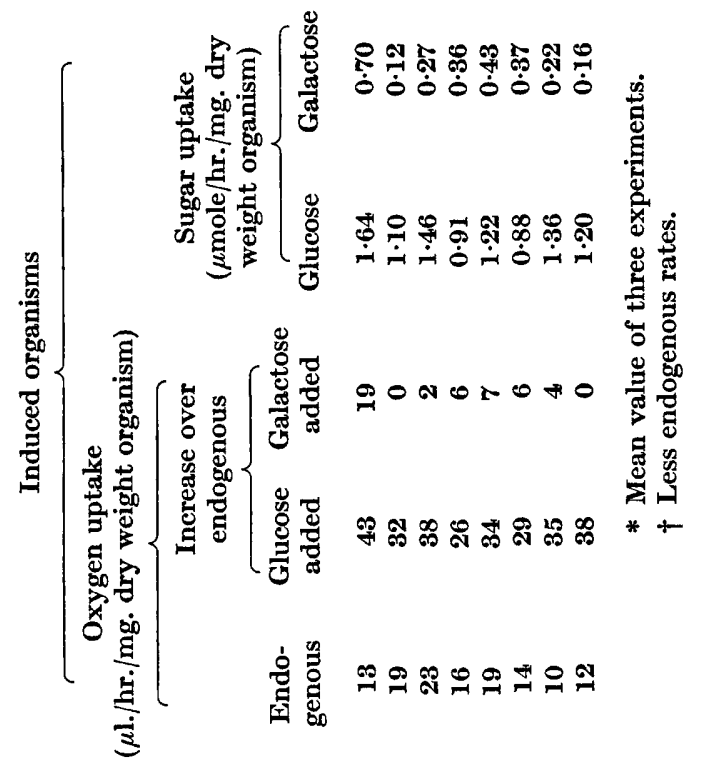

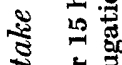
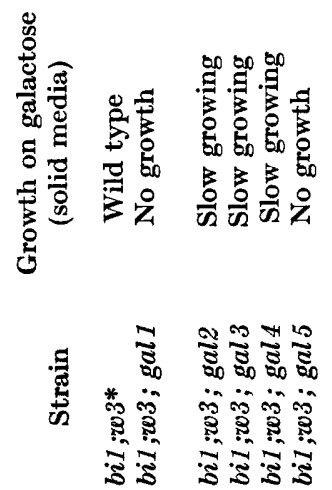
which hyphae grow at the same rate as the wild type but are far fewer in number and form characteristic sparse colonies. All the galactose mutants at a locus are of the same phenotype and five mutants representing each of the loci (called gal 1 to gal 5) were tested for their ability to metabolize galactose after induction of glucose-grown organisms (Table 4).

As expected the mutants all metabolized glucose at rates much the same as the original strain but showed defects in their uptake and oxidation of galactose. These defects may be correlated with the phenotype of the mutants. Differences between the mutants and wild type in the metabolism of galactose are most clearly shown when activities are expressed as the ratios of the rates of galactose to glucose uptake or oxidation (Table 4). Total mutants (gal 1, gal 5) took up galactose at about onethird the rate of the wild type and oxidized the sugar at markedly slower rates. The slow-growing mutants (gal 2, gal 3, gal 4) took up galactose at the same rate as the wild type but oxidized the sugar at about one-half the rate of the wild type.

\section{DISCUSSION}

High endogenous metabolic rates and the assimilation of substrate are general features of mould metabolism (Cochrane, 1958); Aspergillus nidulans conforms to this pattern. The mycelial habit has made moulds unpopular material for biochemical work but in the case of $A$. nidulans small mycelial pellets are satisfactory for whole cell experiments and are good starting material for the preparation of cell-free extracts.

Comparison of these results for $A$. nidulans with the classical work of Stephenson on Escherichia coli (Stephenson, 1949) and Saccharomyces cerevisiae (Stephenson \& Yudkin, 1936) reveals similarity of the overall metabolism of galactose in all three organisms. Relative to glucose, galactose is a poor carbon source for growth; it is oxidized by galactose-grown organisms at about one half the rate of glucose and the enzyme systems are inducible. However, D-fucose, which is a good inducer in $E$. coli (Buttin, 1961) is only one-third as effective as equimolar concentrations of D-galactose in $\boldsymbol{A}$. nidulans. A constitutive galactose permease has been described in $E$. coli (Horecker, Thomas \& Monod, 1960). The rapid initial uptake of galactose by adapted organisms and the slow uptake by non-adapted organisms suggests an inducible permease in $A$. nidulans but requires direct investigation by using ${ }^{14} \mathrm{C}$ galactose.

All of the galactose mutants examined metabolize glucose normally as would be expected from their normal growth on it. Isolation of mutants which fail to grow upon a specific carbohydrate may therefore be expected to exclude organisms with a defect in their general metabolism of carbohydrates, as found among bacterial mutants isolated by a negative fermentation reaction on eosin methylene-blue agar (Lederberg, Lederberg, Zinder \& Lively, 1951; Lederberg, 1960).

The two distinct phenotypes found among the Aspergillus nidulans galactose mutants may probably be correlated with the position of the metabolic lesion. The slow-growing mutants take up galactose at the same rate as the wild type but oxidize it at about half the wild-type rate. About $80 \%$ of exogenous galactose is assimilated and if this assimilation takes place through uridine diphosphogalactose (Kalckar, 1958) it is possible that the slow growers are defective in a metabolic step 
between this compound and glucose-1-phosphate. On the other hand, the nongrowing mutants, which take up galactose at about one-half the wild type rate but only oxidize it at $10 \%$ of the rate of the latter, may be defective in a metabolic step before uridine diphosphogalactose.

I thank Professor D. D. Woods, F.R.S., and Dr June Lascelles for their interest and advice. The author was a Guinness Research Fellow in Microbiological Biochemistry during the work, which was also aided by grants to the Department from the Rockefeller Foundation and the United States Department of Health, Education and Welfare. The excellent technical assistance of $\mathrm{Mr}$ B. Bailey is gratefully acknowledged.

\section{REFERENCES}

Burrin, G. (1961). Some aspects of regulation in the synthesis of the enzymes governing galactose metabolism. Cold Spr. Harb. Symp. quant. Biol. 26, 213.

Cochrane, V. W. (1958). Physiology of Fungi, 1st edn. New York: John Wiley.

Fukasawa, T., Jokura, K. \& Kurahashi, K. (1962). A new enzymic defect of galactose metabolism in Escherichia coli $\mathrm{k12}$ mutants. Biochem. biophys. Res. Comm. 7, 121.

Fukasawa, T. \& Nikaido, H. (1961). Galactose mutants of Salmonella typhimurium. Genetics, 46, 1295.

Hockenhuld, D. J. D. (1950). Studies in the metabolism of mould fungi. Preliminary study of the metabolism of carbon, nitrogen and sulphur by Aspergillus nidulans. J. exp. Bot. 1, 194.

Horecker, B. L., Thomas, J. \& Monod, J. (1960). Galactose transport in Escherichia coli. 1. General properties as studied in a galactokinaseless mutant. J. biol. Chem. 235, 1580.

Huggett, A. St G. \& Nixon, D. A. (1957). Enzymic determination of blood glucose. Biochem. J. 66, 12 P.

KalCKAR, H. M. (1958). Uridine diphospho-galactose: metabolism, enzymology and biology. Advanc. Enzymol. 20, 111.

KALCKAR, H. M. (1959). Biochemical genetics as illustrated by hereditary galactosaemia. In Biochemistry of Human Genetics, p. 23. Ed. by G. E. W. Wolstenholme and C. M. O'Connor. London: Churchill.

KalCKar, H. M., Kurahashi, K. \& Jordan, E. (1959). Hereditary defects in galactose metabolism in E. coli mutants. 1. Determination of enzyme activities. Proc. nat. Acad. Sci., Wash. 45, 1776.

LEDERBERG, E. M. (1960). Genetic and functional aspects of galactose metabolism in Escherichia coli K 12. Symp. Soc. gen. Microbiol. 10, 115.

Lederberg, J., Lederberg, E. M., Zinder, N. D. \& Lively, E. R. (1951). Recombination analysis of bacterial heredity. Cold Spr. Harb. Symp. quant. Biol. 16, 413.

Monod, J. (1942). Recherches sur la croissance des cultures bactériennes. Paris: Herman.

Nelson, N. (1944). A photometric adaptation of the Somogyi method for the determination of glucose. J. biol. Chem. 153, 375.

Pontecorvo, G. \& KäFer, E. (1958). Genetic analysis based on mitotic recombination. Advanc. Genet. 9, 71.

Pontecorvo, G., Roper, J. A., Hemmons, L. M., Macdonald, K. \& Bufton, A. W. J. (1953). The genetics of Aspergillus nidulans. Advanc. Genet. 5, 141.

Roberts, C. F. (1959). A replica plating technique for the isolation of nutritionally exacting mutants of a filamentous fungus (Aspergillus nidulans). J. gen. Microbiol. 20, 540.

RoBerts, C. F. (1963). The genetic analysis of carbohydrate utilization in Aspergillus nidulans. J. gen. Microbiol. $31,45$.

RoBichon-Szulmajster, H. DE (1958). Induction of enzymes of the galactose pathway in mutants of Saccharomyces cerevisiae. Science. 127. 28. 
Shepherd, C. J. (1956). Pathways of cysteine synthesis in Aspergillus nidulans. J. gen. Microbiol. 15, 29.

Singh, J. \& Walker, T. K. (1956). Changes in the composition of the fat of Aspergillus nidulans with age of the culture. Biochem. J. 62, 286.

Soffer, R. L. (1961). Enzymatic expression of genetic units of function concerned with galactose metabolism in Escherichia coli. J. Bact. 82, 471.

Stephenson, M. (1949). Bacterial Metabolism, 3rd edn. London: Longmans Green and Co.

Stephenson, M. \& YudKin, J. (1936). Galactozymase considered as an adaptive enzyme. Biochem. J. 30, 506.

Umbreit, W. W., Burris, R. M. \& Stauffer, J. F. (1949). Manometric Techniques; revised edn. Minneapolis: Burgess Publishing Co.

YARMolinsky, M. B., Jordan, E. \& WeismeYer, H. (1961). Regulatory mechanisms in the synthesis of enzymes of galactose metabolism. 1. Co-ordinate repression and derepression of the 'galactose sequence'. Cold Spr. Harb. Symp. quant. Biol. 26, 217. 